\title{
(Des)legitimando jerarquías sociales, profesionales y cognitivas. Conocimiento y prácticas científicas en los procesos de inclusión-exclusión
}

\author{
Jorge Molero-Mesa $(*)$ e Isabel Jiménez-Lucena $(* *)$ \\ $\left(^{*}\right)$ Centre d'Història de la Ciència. Unitat d'Història de la Medicina. Facultat de Medicina, \\ Universitat Autònoma de Barcelona. Jorge.Molero@uab.cat \\ ${ }^{(* *}$ Unidad de Historia de la Medicina. Facultad de Medicina. Universidad de Málaga. \\ isajimenez@uma.es
}

Dynamis

[0211-9536] 2013; 33 (1): 13-17

El tema que proponemos en este monográfico ${ }^{1}$ se enmarca en los desarrollos conceptuales y teóricos que han tenido lugar en las últimas décadas acerca de los procesos de inclusión y exclusión social, ampliando las fronteras y alcances interpretativos de las propuestas elaboradas a lo largo del siglo XX en torno a distintas formas de discriminación social ${ }^{2}$. Estos acercamientos, dentro de una nueva visión del mundo globalizado que se caracterizaría por su tendencia a dividir las sociedades y las personas en «incluidos»y «excluidos», servirían para preguntarse por grupos socialmente desfavorecidos y los mecanismos por los cuales han sido situados en esa posición en la que son total o parcialmente excluidos de participar en la sociedad en la que viven ${ }^{3}$. Los límites interpretativos fueron parcialmente ampliados con la consideración de que los mecanismos de inclusión y exclusión no

\footnotetext{
1. Todos los trabajos de este dossier se han desarrollado en el marco de los proyectos HAR200913389-C03-01 y HAR2009-13389-C03-03 financiados por el Ministerio de Economía y Competitividad.

2. Durkheim, Émile. The division of labour in society. New York: Free Press; 1964; Weber, Max. Economía y sociedad. México: Fondo de Cultura Económica; 1944; Murphy, Raymond. Social closure: the theory of monopolization and exclusion. Oxford: Clarendon Press; 1988; Parkin, Frank. The social analysis of class structure. London: Tavistock; 1974.

3. Rawal, Nabin. Social Inclusion and exclusion: A review. Dhaulagiri Journal of Sociology and Anthropology. 2008; 2: 161-180; Castells, Manuel. La era de la información. Fin del Milenio. Vol. 3, México: Siglo XXl; 2001.
} 
son lineales, sino complejos y múltiples y actuarían de forma multidimensional en todos los aspectos característicos de las sociedades en las que se desarrollan (económicos, sociales, culturales o políticos). Esta redefinición nos permite considerar en este ámbito el estudio tanto de lo simbólico y lo imaginario como de lo material, como mecanismos que conforman un complejo entramado en las lógicas de inclusión y exclusión (representaciones, experiencias) ${ }^{4}$. En el caso de la exclusión se tratarían de prácticas discriminatorias directas e indirectas así como mecanismos ocultos de exclusión (cultura patriarcal, construcción de estereotipos, dualidades excluyentes). Las lógicas de inclusión por su parte serían diversas y con diferentes justificaciones y modos de pensamiento (derechos individuales, derechos humanos, justicia social o perspectivas funcionalistas).

Sin embargo, nosotros compartimos la idea de que los procesos de inclusión y exclusión social son simultáneos y no necesariamente opuestos, y entendemos que la oposición dualista entre estos dos conceptos limita el análisis de las contradicciones que se producen en la multidimensionalidad característica de la exclusión social y de las paradojas de procesos simultáneos de inclusión y exclusión. De esta forma, si nos limitamos a esta dualidad, no se llegaría a comprender bien las diferencias intergrupales ni los mecanismos de control que se desarrollan para mantenerlas. Esta oposición lleva a valorar como positiva toda inclusión y como negativa toda exclusión y, por tanto, a la simplificación de una relación tan compleja ${ }^{5}$ que para algunos autores constituye la base de las representaciones del sistema social ${ }^{6}$. Desde nuestra perspectiva, los procesos de inclusión y exclusión, se presentan, por el contrario, como un continuum con varios extremos emergiendo indistintamente, lo que nos permite entender cómo individuos y grupos, pueden ser incluidos en unos ámbitos y excluidos en

4. Bourdieu, Pierre. La miseria del mundo. Barcelona: Akal; 1993.

5. Bohn, Cornelia. Inclusion and exclusion: Theories and findings. From exclusion from the community to including exclusion. In: Gestrich, A.; Raphael, L.; Uerlings, H., eds. Strangers and poor people. Changing patterns of inclusion and exclusion in Europe and the Mediterranean world from Classical antiquity to the present day. Frankfurt: Peter Lang; 2009, p. 35-53. Pradhan, Rajendra. Understanding social exclusion and social inclusion in the nepalese context: some preliminary remarks. Workshop Understanding social inclusion and exclusion: theories, methodologies and data. Kathmandu; 2006 [citado 20 Jun 2012]. Disponible en: http://www. socialinclusion.org.np/index/files/Understandng_Social_Inclusion_and_Exclusion_BY_Rajendra_Pradhan.pdf

6. Luhmann, Niklas. Inclusión-exclusión. In: Complejidad y modernidad: de la unidad a la diferencia. Madrid: Trotta; 1998, p. 167-195. 
otros $^{7}$ o cómo la inclusión social de unos se ha construido frecuentemente sobre la exclusión social de otros ${ }^{8}$. Así, dichos procesos estarían en continua negociación adquiriendo un papel relevante los movimientos de oposición al «cierre social» que cuestionarían la limitación al acceso a recursos materiales y simbólicos, constituyéndose en discursos y prácticas de subversión y transformación de estructuras y subjetividades. Estas actuaciones harían posible diferentes significaciones ligadas a la participación de diversos grupos sociales en las dinámicas de inclusión-exclusión que, demandando diferentes tipos de reivindicaciones, tendrían un papel fundamental en el desarrollo de dichas dinámicas 9 .

Por otro lado, hoy día ya nadie discute el importante papel que jugaron los postulados científico-sanitarios en las dinámicas de inclusión-exclusión social en la sociedad burguesa occidental. De esta forma, se ha considerado el biopoder como un instrumento sofisticado de represión y control social equivalente a los utilizados en las sociedades premodernas como fue el discurso religioso o el castigo físico ${ }^{10}$. Las formas de exclusión de las sociedades modernas son a la vez de inclusión y se configuran a través del establecimiento de distancias controladas mediante la supervisión más que por la separación física del individuo, tal como defienden las teorías de la desviación ${ }^{11}$. Y, así, el concepto moderno de salud ha presentado un enorme potencial político para el pensamiento hegemónico ya que, desde la medicina positiva, podía ser definido científicamente a la par que se despojaba al concepto de enfermedad de su etiología social y, por tanto, de su peligrosidad revolucionaria. Este nuevo concepto-herramienta fue concebido para investir a la medicina como la disciplina de la reforma social que, a través de sus agentes, actuaría de mediadora en las dinámicas de inclusión-exclusión al ofrecer al poder establecido la utilización de la ciencia y la tecnología como herramientas para intervenir de forma normativa en

\footnotetext{
7. Jackson, Cecile. Social exclusion and gender: Does one size fit all? The European Journal of Development Research. 1999; 11 (1): 125-146.

8. Rawal, n. 3.

9. Garcés, Laura; Lucero, Marcelo; Estévez, Fernanda et al. Visiones teóricas acerca de la ciudadanía social. Kairos. 2006; 10 (18): 1-11, Jelin, Elizabeth. Igualdad y diferencia: dilemas de la ciudadanía de las mujeres en América latina. Ágora. 1997; 3 (7): 189-214.

10. Foucault, Michel. Vigilar y castigar. Madrid: Siglo XXI; 1982. Huertas García-Alejo, Rafael. Los laboratorios de la norma. Medicina y regulación social en el estado liberal. Barcelona: Ed. Octaedro-CSIC; 2008.

11. Foucault, n. 10
} 
los problemas sociales. En efecto, los postulados médico-sociales, una vez incorporadas las doctrinas eugenésicas, dotarían al biopoder de la potestad de legitimar de forma científica la desigualdad humana, haciéndola compatible con los conceptos de «igualdad»y «libertad» del ideario liberal ${ }^{12}$.

Ahora bien, no podemos olvidarnos de la participación de esos movimientos de oposición a los que antes nos hemos referido y que a través de distintos agentes sociales introducen la complejidad y la multidimensionalidad en las lógicas de inclusión-exclusión. Con estas premisas, este dossier presenta cuatro artículos que pretenden mostrar las dinámicas legitimadoras y deslegitimadoras de jerarquías sociales, profesionales y cognitivas que se ponen en marcha en los procesos de inclusión-exclusión. Para ello, se ha descentrado el lugar de enunciación del conocimiento científico a través del estudio de discursos y prácticas en torno a los fenómenos de salud y enfermedad en el seno de la sociedad española contemporánea en tres ámbitos de actuación que se complementan entre sí.

El mundo obrero anarquista es el primer ámbito en el que se propone, a través de dos artículos, un acercamiento al papel que desempeñaron los discursos y las prácticas médicas en los procesos de inclusión-exclusión social, tanto desde el punto de vista del pensamiento hegemónico como del pensamiento subalterno libertario. El primer trabajo (Jorge Molero e Isabel Jiménez) analiza las complejas relaciones establecidas, a lo largo del primer tercio del siglo XX español, entre los militantes anarcosindicalistas y los profesionales de la medicina con inquietudes libertarias; todo ello dentro de la polémica establecida en aquellos momentos en el seno de la Confederación Nacional del Trabajo acerca del papel que el técnico y el intelectual desempeñaban en el sistema liberal y el que deberían jugar para llegar a alcanzar una sociedad anarquista. En este caso, la participación/ no-participación se nos muestra como elemento central de los procesos incluyentes-excluyentes relacionados con el conocimiento científico. El segundo trabajo (Carlos Tabernero, Isabel Jiménez y Jorge Molero), aborda la relación que los profesionales médicos establecieron con el mundo anarquista a través de la divulgación de sus conocimientos técnicos en la revista Estudios, centrándose en la sección de «Preguntas y respuestas»a

12. Molero Mesa, Jorge; Jiménez Lucena, Isabel. «Otra manera de ver las cosas». Microbios, eugenesia y ambientalismo radical en el anarquismo español del siglo XX. In: Miranda, Marisa; Vallejo, Gustavo, eds. Darwinismo social y eugenesia. Derivas de Darwin: cultura y política en clave biológica. Buenos Aires: Siglo XXI, Ed. Iberoamericana; 2010, p. 143-164. 
cargo de Roberto Remartínez (1895-1977). Sus resultados nos muestran la existencia de una periferia cultural anarcosindicalista convertida en un espacio inclusivo de diálogo dónde se intentan superar las fronteras establecidas entre expertos y no-expertos como forma de dominación social.

El segundo ámbito explorado es el profesional sanitario. El trabajo de José Manuel Gutiérrez analiza la utilización de la ciencia como herramienta legitimadora de la jerarquía ocupacional y nos ofrece una imagen inédita de la albeitería, fuertemente denostada por una historiograf ía hagiográfica veterinaria no tan lejana. La disputa que a mediados del siglo XIX se estableció en España entre albéitares y veterinarios y que acabaría con la desaparición de los primeros y la definitiva consagración de la profesión veterinaria nos muestra como las dinámicas de inclusión-exclusión actuaron, en este caso, bajo la influencia determinante legitimadora que otorgaba el conocimiento científico. Una estrategia de demarcación ocupacional basada en el derecho consuetudinario, el conocimiento experto y la integración y aceptación del albéitar en el agro español, no consiguió frenar el declive de la albeitería hasta su desaparición y olvido.

Por último, en el ámbito médico-farmacéutico, el trabajo de Sara Lugo analiza los mecanismos de inclusión-exclusión subyacentes a las estrategias de legitimación de los productos antituberculosos que producía el instituto Ravetllat-Pla a partir de una teoría científica heterodoxa. El detalle con el que son estudiados los acontecimientos que acaecieron tras la presentación en sociedad de esta peculiar teoría bacteriológica de la tuberculosis permite a la autora desvelar la multiplicidad de las dinámicas de inclusiónexclusión implicadas mostrando sus diversas vertientes no sólo científicas y económicas sino también políticas e ideológicas.

Con los artículos que presentamos en este dossier esperamos contribuir a identificar, en el ámbito del pensamiento científico y médico, los elementos que componen las diversas lógicas de inclusión y exclusión como parte de la estructura profunda de la dominación, así como a comprender las distintas formas en que, a través de esta perspectiva, las dinámicas de inclusión y exclusión se constituyen en relaciones de poder. 